Boston University School of Law

Scholarly Commons at Boston University School of Law

Faculty Scholarship

1976

\title{
Ethical Relativism and the Problem of Incoherence
}

David B. Lyons

Boston Univeristy School of Law

Follow this and additional works at: https://scholarship.law.bu.edu/faculty_scholarship

Part of the Law Commons

\section{Recommended Citation}

David B. Lyons, Ethical Relativism and the Problem of Incoherence, in 86 Ethics 107 (1976).

Available at: https://scholarship.law.bu.edu/faculty_scholarship/373

This Article is brought to you for free and open access by Scholarly Commons at Boston University School of Law. It has been accepted for inclusion in Faculty

Scholarship by an authorized administrator of Scholarly Commons at Boston University School of Law. For more information, please contact lawlessa@bu.edu. 


\section{Ethical Relativism and the Problem of Incoherence*}

\section{David Lyons}

Cornell University

It is natural to suppose that "ethical relativism" names a single type of theory that either makes good sense or none at all. Opponents of relativism may therefore be expected to argue that it is an incoherent doctrine. Some have done so, understanding it as the combination of blatantly inconsistent claims. Recently, Gilbert Harman has objected to such a strategy of "dissuasive definition" and has shown its inadequacies by developing a theory that is recognizably relativistic while lacking any obvious inconsistencies. ${ }^{1}$ It may therefore seem as if ethical relativism is immune to such charges and can continue to demand our respect.

I agree with Harman that relativistic theories do not uniformly lapse into incoherence, but there nevertheless remain reasons for suspecting many relativistic theories of being untenable - reasons not of accidental formulation but rooted deeply in certain ways of thinking about morality. As a consequence, whole classes of relativistic theories may well prove to be incoherent.

In this paper I shall explore the nature and extent of one important threat of incoherence to ethical relativism. I shall sketch the source of that particular threat, I shall show how relativistic theories differ in their vulnerability to it, and I shall suggest that our fears for relativism may be tempered slightly. Then I shall consider two ways in which relativists might try to avoid (or might luckily succeed in avoiding) such incoherence- that is, by resorting to "relativistic" notions of justification in ethics and by construing moral judgments as having a hidden relativistic structure.

THE PROBLEM

Suppose that Alice and Barbara have been discussing Claudia's proposed abortion. They know Claudia well, and they agree about the circum-

*I began working on this paper while a Fellow of the Society for the Humanities at Cornel University. I am grateful for that institution's most congenial support as well as for the many helpful comments I have received from many persons when reading drafts at Vassar College, the Creighton Club, and at Brown, Cornell, Michigan, and Utah Universities.

1. Gilbert Harman, "Moral Relativism Defended," Philosophical Review 84 (January 1975): $3-22$

107 stances and the likely consequences of the act. But they disagree in their evaluations, Alice maintaining that it would be wrong and Barbara that it would not be wrong for Claudia to have the abortion.

Now, according to some theories about morality, both Alice and Barbara could be making perfectly valid moral judgments. Some anthropologists have suggested, for example, that one's judgment is valid if, and only if, it agrees with the norms or code of one's social group. ${ }^{2}$ These writers evidently think it possible for Alice and Barbara to belong to different groups, their groups to have codes that differ about abortion, and their respective judgments to conform to their respective group codes. They are therefore committed to regarding both judgments as valid in some cases. Some philosophers have held that one's moral judgment is fully justified if it accords with the relevant facts and with principles to which one would freely subscribe on due reflection under ideal conditions. ${ }^{3}$ Since it is admittedly possible for different persons to embrace differing principles even under ideal conditions, such theorists are committed to endorsing both judgments - that Claudia's act would be wrong and that Claudia's act would not be wrong-in some possible cases.

This clearly generates a problem which, while tacitly acknowledged in the philosophical literature, has not been discussed directly. The judgments made by Alice and Barbara appear to be logically incompatible. They might be straightforward contradictories - unless "wrong" and "not wrong" have restricted ranges of application, in which cases they would seem to be at least strict logical contraries. Appearances can be misleading, of course, but the relevant considerations are not negligible; they involve not merely surface grammar but also the conviction shared by laymen and philosophers that only one of these judgments could possibly be right and also our ways of discussing such cases, which include advancing reasons that are held to warrant drawing or refusing one judgment or the other. ${ }^{4}$ Such theories seem to endorse (at least the possibility of) contradictions. Unless something further can be said, they are incoherent and may be committed to the philosophical scrap heaps.

For this reason, or some other, relativists often claim, in effect, that such judgments are not logically incompatible; so of course we cannot assume the opposite here. For convenience, however, I shall refer to such pairs of judgments as "conflicting," thus reflecting the presumption that they are logically incompatible while leaving open our final judgment on the nature of the conflict between them.

2. See, for example, W. G. Sumner, Folkways (Boston: Ginn \& Co., 1940); M. J. Herskovits, Man and His Works (New York: Alfred A. Knopf, 1948), chap. 5, and Cultural Anthropology (New York: Alfred A. Knopf, 1955), chap. 19.

3. Sec, for example, R. M. Hare, The Language of Morals (Oxford: Clarendon Press, 1952) and Freedom and Reason (Oxford: Clarendon Press, 1963)

4. For an emphatic presentation of such points in another connection, see Carl Wellman, "Emotivism and Ethical Objectivity," American Philosophical Quarterly S (April 1968): 90-92. 
It should also be noted that I shall use the term "incoherence" generally rather than "inconsistency" and shall speak of validity rather than truth, because I wish to include within this survey certain ethical theories which deny that moral judgments are either true or false. Since these theories nevertheless regard moral judgments as subject to significant validation or justification, they too are affected by the same threat of incoherence.

TWO KINDS OF RELATIVISM

Not all relativistic ethical theories flirt with this sort of incoherence. We can see this when we try to disambiguate the anthropologists' suggestions. Generally speaking, the idea they embrace is that the existing norms of a social group are the only valid basis for moral appraisals. Beyond this, their suggestion is not entirely clear. Is it that the norms within each group must be used in judging conduct within that group? Or is it that such norms directly govern all the judgments made by members of the group? (There are other possibilities, but these are the most plausible and will serve our purposes.) It makes a great deal of difference which is meant.

Take the first possibility, the one most strongly suggested by the anthropologists, which I shall call agent's-group relativism. It may be understood as the notion that an act is right if, and only if, it accords with the norms of the agent's group. Now, such writers are anxious to impress on us that there are many different social groups, each group having its own norms which can be different from those of other groups. Against that background it seems reasonable to regard such a theory as relativistic, for it recognizes (or at least countenances) a number of different, independent bases for moral appraisals.' Nevertheless, such a theory seems not to validate conflicting moral judgments, because each group is regarded, so to speak, as a separate moral realm. If we wish to judge a given act, such as Claudia's proposed abortion, this theory tells us to apply the norms of her social group. It therefore seems to imply that any single item of conduct can correctly be judged in one and only one way. ${ }^{6}$

The second possible interpretation of the anthropologists' idea can be called appraiser's-group relativism because it says, in effect, that a moral judgment is valid if, and only if, it accords with the norms of the appraiser's social group. Such a theory does seem to validate conflicting moral judgments, for reasons we have already noted. Any single act can be judged by people in different social groups, and so judgments of Claudia's

5. As Sumner makes clear and Herskovits implies, this does not mean that the norms themselves are beyond evaluation. Their approach to the norms is, in fact, broadly utilitarian and thus (in a significant sense) nonrelativistic. (Sumner seems to reason that the function of the norms is adaptation to the circumstances, that someching is good insofar as it performs its function well, and thus that norms are good insofar as they are adapted to circumstances-in which case, he assumes, they serve societal welfare.) But the appraisal of conduct is treated as an independent matter, governed by existing norms. (Sumner seems to struggle with the tension here, tying "immorality" to /conformity and yet praising enlightened dissent.)

6. I am here ignoring the possibility that some norms of a group may themselves conflict
110 Ethios

proposed abortion, for example, can be governed by different norms. Both Alice's and Barbara's conflicting judgments might well be validated by this theory.

These two theories give us differing instructions for judging conduct within other groups. Both theories tolerate more than one basis for moral appraisals, but the appraiser theory allows differing standards to have overlapping applications ${ }^{7}$ while the agent theory apparently does not.

This contrast has, of course, nothing to do with the rampant conventionalism of such theories; it can be found in other families of relativistic theory too. Consider, for example, the individualistic philosophers' theory that was noted at the outset. This says, in effect, that one's moral judgment is valid if, and only if, one would accept it under certain hypothetical circumstances (such as knowing all the relevant facts) that are conceived of as ideal for deciding upon one's moral principles. Now, there is no guarantee that different individuals will subscribe to the same principles, even under "ideal" conditions, so such a theory is relativistic. This is also an appraiser theory and could well validate conflicting moral judgments. By now we can also see the possibility of a contrasting agent theory, which says that a person's conduct must be judged by the principles to which he himself would subscribe under such ideal conditions. This theory would not seem to validate conflicting moral judgments. ${ }^{8}$ These two theories give us differing instructions for judging another person's conduct, and the appraiser version does, while the agent version apparently does not, flirt with incoherence.

What seems to make all these theories qualify as relativistic is their acceptance of more than one set of basic moral standards (social norms or personal principles, for example). But some allow these standards to have overlapping applications, while others do not, and this determines whether a theory will endorse conflicting moral judgments. The threat of incoherence that we are investigating, therefore, does not affect relativistic theories equally.

I have not said that it does not affect agent theories at all because such theories, despite their apparent intentions, can sometimes countenance conflicting judgments too. Consider agent's-group relativism. It may seem secure, so long as we forget that individuals can belong to more than one social group at any time. While suggesting their group-oriented theories, anthropologists have seemed strangely insensible of the fact that, even within the relatively small societies to which they typically refer, social classes, families, and other real social groups (of the sort social scientists are concerned to investigate) are maintained.? And social norms can be ascribed

7. One could eliminate this feature of the theory, for example, by invalidating "cross-cultural" judgments. But for our purposes we can ignore this possibility.

8. Harman's theory, so far as it goes (it concerns only one type of judgment about conduct), has the basic features of an agent theory, since it allows no more than one set of values (to which one is a tacit subscriber) to govern one's conduct.

9. And the relations between social groups, such as economic exploitation, suggest how naive 
to many such groups. Most important, one can belong to groups that have differing values (as well as be disaffected from values that prevail within a group to which one continues to belong). Claudia, for example, might be in a church that condemns abortion and at the same time in a family, peer group, voluntary organization, social class, or political community that condones it. Now, the basic notion underlying agent's-group relativism seems to be that membership in a group makes its prevailing standards validly applicable to one's conduct. If so, the theory implies that Claudia's proposed abortion should be judged by the norms of all the groups to which she belongs. This would allow it to validate conflicting moral judgmentsindeed, to both validate and invalidate a single judgment.

Such complications clearly can afflict other agent theories too. Any theory is vulnerable unless it guarantees that differing standards have no overlapping applications to specific cases. Of course, it is possible to secure this, if one is willing to pay the price of necessary revisions. But it is not always clear how to change a theory so as to avoid such embarrassments, while preserving its original point. Most important, it remains to be seen whether incoherence can be avoided in a truly nonarbitrary manner. If a theory has incoherent implications, it is, presumably, quite strictly untenable. But one that avoids incoherence arbitrarily, through ad hoc revisions lacking any independent rationale, cannot be much more tenable. I shall revert to this point later. Meanwhile, I shall restrict my attention to appraiser theories, since the relevant problem affects them primarily. Agent theorists must be wary, but their difficulties present us with no new problems to consider.

\section{THE CHARGE OF INCOHERENCE QUALIFIED}

We may need to temper slightly our ideas about the possible incoherence of relativistic theories. Even when a theory is in the worst straits, and seems to tell us that contradictory judgments are both true, there are reasons for hesitating to call that theory incoherent and hence untenable. Since the present point has more general significance than its bearing upon relativism, it may be best to explain it in relation to another sort of theory that is sometimes suspected of incoherence-ethical egoism.

It may be said that egoism is incoherent because it can be used to generate contradictory judgments about cases in which the interests of different individuals conflict. But consider an egoist who also believes in the natural harmony of human interests - that is, between the overall, long-term interests of differing persons. He denies, in effect, that there ever are any cases of the sort just mentioned, which are responsible for the alleged incoherence of his principle. From his overall position, which includes this belief in the natural harmony of human interests as well as ethical egoism, it seems impossible to derive the contradictory judgments in question. If so, his position cannot fairly be charged with incoherence on such grounds. And yet his position includes the egoistic principle. If that were incoherent-if it had literally inconsistent (or otherwise incoherent) implications - then presumably we could still generate contradictions from it, even when it is conjoined with some contingent claim. Since we cannot, it seems to follow that such judgments are not entailed by principles like egoism alone, and thus that the egoistic principle itself cannot fairly be charged with incoherence. The relevant implications derive from more complex positions, including beliefs about the relevant facts; and so it is these positions which may or may not be charged with incoherence.

Now, I do not mean to suggest that the implications of a principle are limited to actual cases. This cannot be right, since they are thought to cover possible cases too, such as Claudia's proposed abortion. But the foregoing argument does not restrict their implications to actual cases. My suggestion is that we must differentiate between what can strictly be ascribed to a principle alone and what can only be ascribed to a larger position. Nor do I mean to suggest that one must positively believe in the divergence of different persons' interests in order to be charged with incoherence for holding such a principle. Perhaps an egoist with an open mind about the relevant facts could fairly be charged with having an incoherent position (assuming the principle does in fact yield inconsistent judgments for such cases), because such a person would accept, in effect, the possibility of contradictions. But there seems to be a significant sense in which an egoist who believes in the natural harmony of human interests is not committed to such judgments. Clearly, I have only scratched the surface of a complex question on which more work is needed. For the sake of argument here, let us suppose my suggestion is correct.

If it is, it would seem to follow that a relativistic theory cannot be regarded as incoherent simply because it can be used to generate logically incompatible judgments in the ways we have considered (supposing for the moment that they are strictly incompatible or that a theory so construes them). For, someone might combine a relativistic theory with certain contingent beliefs which imply that the relevant cases never will occur, thus effectively blocking the offending judgments. For example, an appraiser'sgroup relativist might conceivably maintain that every social group inevitably shares the same set of basic values; someone endorsing the individualistic analogue of that theory might believe that identical basic values must be ascribed to all persons. Such beliefs would block the validation of conflicting moral judgments by such theories. If so, not only the overall positions but also the principles they contain cannot fairly be charged with incoherence. Strictly speaking, such principles would not be rationally untenable.

But even if we accept this line of reasoning, the resulting concession to relativism would seem minimal. A relativist could not deliberately exploit the point, for he could not save his real views from incoherence by merely mouthing certain saving beliefs. To profit from the point, he must sincerely hold those beliefs. (As I have suggested above, he cannot save himself by having an open mind on the matter, for that would still leave him 
tolerant of contradictions.) And we are unlikely to find such a relativist, because the required beliefs are not only implausible but would deprive his principle of what he is most likely to regard as part of its point-namely, the basis for recognizing several independent grounds for moral appraisals. Moreover, even if there were such a relativist, the possibility of his holding such a principle would not remove its stigma for anyone who lacked his sort of convictions about the relevant facts. For anyone without his special beliefs, such a principle would be rationally untenable. For these reasons, I shall hereafter ignore this qualification on the charge of incoherence.

\section{RELATIVISTIC JUSTIFICATION}

The threat of incoherence arises for the relativist because he seems to endorse logically incompatible judgments as simultaneously true. The possible lines of escape therefore seem obvious; he must either show that he is not endorsing them both as true or else deny that the judgments are truly incompatible. The second approach is the standard maneuver, the first being rarely entertained in such a context. The first deserves some special treatment, to which I now turn.

It might appear obvious that a relativist could avoid incoherence if he embraces a noncognitive conception of moral discourse. For, if moral judgments are neither true nor false, it might seem that they could not possibly contradict one another.

There are two reasons for rejecting this suggestion as it stands. In the first place, a relativist cannot simply deny that moral judgments have truth values. He must also regard them as subject to some significant sort of validation or justification and hold that there is more than one basis for such appraisals. It remains to be seen whether the conflicting judgments that he is then committed to endorsing are related in a coherent manner.

In the second place, I wish to separate the issues as far as possible, and so I do not wish to discuss right now (what will be discussed later) whether relativism can be saved if we suppose that apparently conflicting judgments are not really incompatible in the relevant, troublesome cases. Right now we wish to see what difference it might make for a relativist to deny that the relevant conflicting judgments are true, while he nevertheless regards them as logically incompatible. To put the point another way, we wish to see how relativism can fare when it accepts as far as possible the relevant logical appearances - for example, the apparent incompatibility of certain moral judgments that he may wish simultaneously to endorse.

To see what this possibility amounts to, we must shift our focus slightly. What becomes crucial here is not so much the lack of truth values as the character of the relativist's appraisal of moral judgments. Within a noncognitive moral theory, he refrains from endorsing them as true. Is there then a way of endorsing conflicting moral judgments which maintains the spirit of relativism and yet avoids incoherence? I shall argue to the contrary. I shall show, first, how a clearly coherent position that seems relativistic on the surface forsakes relativism entirely. I shall indicate what must be done to transform such a theory into a form of ethical relativism and suggest why that may be impossible. Finally, I shall show how a clearly relativistic theory developed within the present guidelines generates apparently unintelligible results. I will not show that a coherent form of relativism within the current guidelines is impossible, but I will give reasons for supposing that the prospects are not encouraging.

It would be difficult to imagine how to proceed if we did not have Hare's ethical theory to serve as the basis for discussion. At any rate, it seems at first to meet our requirements. Hare regards moral judgments as "prescriptions" for action ${ }^{10}$ and so does not construe them as either true or false. Nevertheless, he takes the apparent logic of moral discourse quite seriously, and he offers an apparently relativistic theory of justification.

It seems fair to say that Hare's analysis of the logic of moral discourse is committed to preserving and explaining most of the logical phenomena, save what seems most intimately connected with the notions of truth and falsity. Hare would seem to regard Alice and Barbara's conflicting judgments about Claudia's proposed abortion as logically incompatible, because he believes that such relations are not restricted to the realm of "factual" assertions. Hare tries to account for these phenomena not despite, but rather by means of, his specific noncognitive theory. Thus, the essential meaning of a moral judgment is alleged to be (something like) its prescriptive force, such as the condemnation of Claudia's proposed abortion (by Alice) or the withholding of such condemnation (by Barbara). The relevant relations between such utterances are held to be substantially the same as the relations between an assertion and its denial. But the details (and of course the soundness) of Hare's theory are not at issue here. The main point is that he wishes to preserve the relevant logical phenomena- to treat such judgments as conflicting in the strictest logical sense.

Hare believes, furthermore, that moral judgments can be justified by subsuming them under general principles from which they can be derived when suitable assumptions are made about the facts. One's judgment can be faulted-shown to be unjustified-if such support is unavailable. But a defense is only as good as the support that is offered. Unless one can show not only that one's factual assumptions are reasonable but also that one's basic moral principles are not arbitrary, it would be implausible to speak of justifying moral judgments. It is therefore important that, on Hare's view, even one's basic principles are subject to a kind of rational criticism. It will suffice for our purposes to note here Hare's original suggestions about such criticism (for his later elaborations do not affect the relevant points).

One must consider the "consequences" of a (basic) principle and the

10. As Hare seems to recognize (The Language of Morals, pp. 20-24), this characterization ignores half of our possible judgments of conduct, such as Barbara's judgment that Claudia's proposed abortion would not be wrong, which is by no means a "prescription" or imperatival. But Hare's general idea could be expanded into a more adequate theory, as Bentham, for example, was aware; see my In the Interest of the Governed (Oxford: Clarendon Press, 1973), chap. 6. 
"way of life" it represents and make a "decision of principle" whether to accept or reject it. If one accepts a principle under those conditions, one's decision is justified: it is neither "arbitrary" nor "unfounded," Hare says, because "it would be based upon a consideration of everything upon which it could possibly be founded." "11

The upshot seems to be a form of appraiser relativism, for moral principles are supposed by Hare to have universal scope, and those emerging from decisions of principle can conceivably diverge. As Hare fully recognizes, whether or not a principle can pass the sort of test he describes is a psychological fact about a given person. The relevant dispositions of individuals can vary, so that two persons might make decisions of principle with differing results (for example, one condemning abortion, the other condoning it); their principles could then be applied most rigorously in conjunction with the same set of true factual beliefs about an action (Claudia's proposed abortion, for example) to obtain what in Hare's view would be fully justified moral judgments, which could not be faulted in any way, though they conflicted.

Does this show that an appraiser theory can endorse logically incompatible judgments without lapsing into incoherence? I believe not. If we interpret Hare's theory of justification in the most natural way, its limited claims hardly deserve to be called "relativistic" (they seem in fact to be perfectly innocuous), while a truly relativistic reinterpretation yields a theory that is difficult to understand, if it is at all intelligible.

Hare's theory of justification seems to concern the conditions under which a person can be justified in making or maintaining a moral judgment. It says nothing whatsoever about the judgment itself (its content). Thus, on Hare's theory, Alice can be justified in judging Claudia's proposed abortion to be wrong, and Barbara can simultaneously be justified in judging Claudia's proposed abortion not to be wrong; but Hare's theory speaks only of their judging, not of the contents of their judgments - that is, that Claudia's abortion would be wrong and that Claudia's abortion would not be wrong.

There is nothing especially "relativistic" about a theory which acknowledges the possibility that two individuals can be justified in making their respective judgments, even when the judgments themselves are (regarded as) logically incompatible. Consider a case outside ethics. Alice might be justified in predicting rain tonight while Barbara is justified in predicting none, because justification here is "relative" (in a perfectly innocuous sense) to such things as evidence and reasons, which two people do not necessarily share. Hare may be understood as claiming that justification in morals is similarly "relative" (so far, in this same perfectly innocuous sense) to individuals' "decisions of principle." But that alone is not ethical relativism, because it is compatible with all that an antirelativist might ever

11. Hare, The Language of Morals, p. 69 .
116 Ethics

desire. Consider Alice's and Barbara's conflicting weather predictions once more. They may both be justified; but one is correct and the other incorrect, regardless of their justifications; that is to say, either it will or will not rain tonight. The parallel supposition in ethics is perfectly compatible with Hare's theory of justification in morals as we have so far construed it. Hare's theory tells us nothing at all about the validity of the judgments themselves. For all we have said so far, it may be the case that Alice's judgment (that is, that Claudia's proposed abortion would be wrong) is correct and that Barbara's conflicting judgment is consequently incorrect.

Now, it may be observed that Hare seems also to believe that moral judgments cannot be, as it were, "objectively" appraised-that they cannot be correct or incorrect independently of the justification one may have for making them. Indeed, his reasons for this belief seem partly to underlie his theory of justification. Hare maintains that "factual" judgments cannot guide conduct, while moral judgments do. He also maintains that moral judgments therefore have (something like) an imperatival character or component, and he assumes that factual judgments must be expressed in the indicative mood. He then argues that "imperatives" cannot be deduced from "indicatives" alone, which he therefore takes as implying that moral judgments cannot be deduced from factual considerations. From this he infers that moral judgments are logically independent of the facts. One must take account of the facts when making moral judgments, but one must also appeal to (imperative-like) general principles. When one arrives at basic principles, arbitrariness is avoided by the sort of rational reflection that is involved in making decisions of principle. Thus, Hare seems to say, the most that we can possibly do by way of appraising moral principles is to subject them to such personal criticism. And this, he believes, is not negligible. It entitles us to talk quite seriously of "justification."

I wish to maintain, however, that we are not obliged to accept this more radical position, even if we endorse a noncognitive conception of moral discourse like Hare's. In the first place, Hare's line of reasoning to his more radical position is fallacious. Hare begs a crucial question by assuming that "factual" judgments must be understood in the indicative while moral judgments must be assimilated to the imperative. This bias seems based on Hare's unwarranted assumption that "factual" judgments, and generally judgments that are properly expressed in the indicative mood, cannot be guides to action. Most important, Hare fails to consider seriously the possibility of logically sound nondeductive arguments from factual premises to moral conclusions. So, Hare has not shown (or even given us any reason to believe) that moral judgments are independent of the facts and cannot be objectively appraised for that (or some other) reason. I have no idea how that might be shown.

In the second place, Hare's noncognitive conception of moral discourse does not seem to preclude the possibility that moral judgments are "objectively" correct or incorrect. It is clear that both Bentham and J. S. Mill, for example, regarded moral judgments as objectively correct or incorrect. And 
there are good reasons for ascribing to them a noncognitive theory of moral discourse roughly like Hare's. ${ }^{12}$ The difference is that they believe what Hare appears to deny - namely, that basic principles are objectively correct or incorrect. The result is not obviously untenable. But perhaps an analogy might help to suggest the possibility of such a position. It is not implausible to regard prudential judgments as objectively correct or incorrect, and this idea would seem to have no bearing on the question of whether prudential judgments require a noncognitive analysis. But if that can be said for prudential judgments, why not for moral judgments too?

In the third place, the idea of combining Hare's innocuously "relativistic" theory of justification with the claim that moral judgments are not themselves objectively correct or incorrect is itseif suspect. Consider what the resulting position would be like. One would be maintaining that Alice can be justified in judging that Claudia's proposed abortion would be wrong, but that the judgment itself - that Claudia's proposed abortion would be wrong - can be neither correct nor incorrect. The suggestion is dubious, partly because the very notion of "relative" justification has its home among items which can be appraised in objective terms (such as weather predictions). Indeed, we seem to get an understanding of what is meant by justifying one's judgments in that "relative" sense partly by contrasting it with objective appraisal of the judgment itself. It is unclear whether the idea of "relative" justification has any proper application, any reasonable interpretation, outside such a context.

The usual suggestions that it does are based on the notion that the best we can do always counts as justification. That idea is endorsed by Hare when he says that a "decision of principle" can be regarded as justified "because it would be based upon a consideration of everything upon which it could possibly be founded." This is much too indulgent, for it would oblige us to regard any totally unjustifiable assertion as completely justified! (This is especially embarrassing to Hare, since he recognizes no good, logically respectable arguments from factual premises to moral principles; thus he seems to encourage the endorsement of principles that are not only without foundation but also indistinguishable, on his own account of justification, from totally unjustifiable positions.)

To transform Hare's theory into a truly relativistic position, therefore, one needs a good argument for denying that moral judgments themselves are objectively correct or incorrect plus an account of how the notion of "relative" justification can nevertheless apply. I have never seen a plausible account of this matter, and I am uncertain, for the reasons indicated above, whether any such account is possible. Let us see if others can meet this challenge.

12. For Bentham, see In the Interest of the Governed, chap. 6; for Mill, one must begin with his System of Logic, bk. 6, chap. xii. Neither writer will seem unambiguous to modern readers; there are textual grounds for the standard view of them as ethical "naturalists." I am only suggesting a possible interpretation that seems interestingly compatible with their antirelativism.
118 Ethics

Meanwhile, I suggest that if we wish to see what a truly relativistic theory of justification would be like within the present guidelines, we must build upon Hare's theory quite differently. I shall use the materials provided by Hare, without suggesting that the results would meet with his approval.

Such a theory would concern the judgments themselves, not one's making or maintaining them. And here I am uncertain of what terms of appraisal to use. It seems misleading to adopt the term "justified," since it most naturally applies to the attitude rather than its object. And we cannot here, within the confines of noncognitivism, speak of truth. So I suggest that we use the term most favored by ethical relativists - "valid"--hoping it will have no misleading connotations.

The theory can be sketched as follows. More than one basis for moral appraisals is recognized, and these make it possible to validate conflicting moral judgments. For purposes of illustration, let us suppose that the bases are decisions of principle and that Alice and Barbara subscribe to differing principles, such that the judgment condemning Claudia's act is validated by Alice's principles while the withholding of such condemnation is validated by Barbara's principles. To avoid irrelevant complications, we assume further that Alice and Barbara each have internally consistent moral positions, in the sense that the principles attributable to one of them cannot be used to both validate and invalidate one of these judgments or to validate both of them.

Difficulties arise when we imagine the following sort of case. Suppose that Barbara's actual judgment, on this occasion, conflicts with the principles to which she would subscribe on due reflection. Her actual judgment is therefore held to be invalid. (This must be possible, or the theory would imply that all actual judgments are valid.) It is important now to see that, so far as such a theory is concerned, the actual judgments made by Alice and Barbara are identical in content; they have the same meaning. (On the particular theory we are using for purposes of illustration, they have the same meaning because they both condemn Claudia's abortion.) Now, the theory appraises judgments in respect to their contents and by reference to personal principles. But, since different persons' judgments can be identical in meaning, the standards that are invoked cannot, so to speak, tell the difference between one person's judgments and another's. So, whether the relativist likes it or not, Alice's principles can be used to appraise Barbara's judgments as well as her own, and vice versa. The upshot is that such a theory allows one and the same judgment (in respect of content) to be both valid and invalid. In the case we have just imagined, the judgment that Claudia's proposed abortion would be wrong is held valid because it accords with (or is derivable from) Alice's principles and invalid because it conflicts with Barbara's. But it is difficult to understand what this might meanthat such a judgment (the judgment itself, not someone's making it) is simultaneously both valid and invalid. ${ }^{13}$

13. The foregoing argument does not, in fact, require that the two judgments have precisely 
One might expect the relativist here to try to relativize the notion of validity. But we are speaking of the contents of judgments, not someone's making them, so it is not clear how that might be done; the innocuously "relative" notion of justification seems out of place, for example. It remains to be seen whether any sensible interpretation can be given to this paradoxical appraisal.

The foregoing arguments do not conclusively show that a truly relativistic theory which accommodates most of the relevant logical phenomena is impossible, but it strongly suggests that conclusion. I therefore tentatively conclude that relativism must reject the apparent logic of moral discourse and resort to more desperate theoretical measures.

\section{REIATIVISTIC ANALYSES}

Relativistic theories that are threatened by incoherence might try to avoid it by claiming that the relevant conflicting moral judgments are not really incompatible. This has, in fact, been suggested by anthropologists when they claim that to say that an act is wrong simply means that the act conflicts with certain norms. ${ }^{14}$ On this approach, appraiser's-group relativism would be modified so that it understands Alice's utterance, "Claudia's proposed abortion would be wrong," to mean that Claudia's contemplated act conflicts with the norms of Alice's group while construing Barbara's assertion, "Claudia's proposed abortion would not be wrong," to mean that Claudia's act would not conflict with the norms of Barbara's group. Now, Alice and Barbara either belong to the same group or they do not. If they do, then the theory regards their judgments as incompatible, which accords with the logical appearances. The troublesome sort of case arises when Alice and Barbara belong to different groups whose respective norms disagree about abortion. The present theory would allow both Alice's and Barbara's judgments to be true but denies that they are incompatible, since one judgment relates the act to one set of norms while the other judgment relates it to another set. In this way, such a theory can avoid endorsing inconsistencies.

Some of the consequences of such theories should not pass unnoticed. On the surface it appears that Alice and Barbara are disagreeing about Claudia's proposed abortion, saying incompatible things about it. But, ac cording to this sort of theory, they are confused if they believe their judg. ments to be incompatible. In fact, the theory says, they are actually talking at cross purposes.

the same meaning. It would suffice if they were so related that their respective negations were logical contraries. But to regard them as identical is to respect the logical appearances as fully as possible.

14. See, for example, Sumner (sec. 439) and Ruth Benedict ("Anthropology and the Abnormal," reprinted in Value and Obligation, ed. R. B. Brandt [New York: Harcourt, Brace \& World, 1961], p. 457).

\section{Ethics}

And consider what the theory says when Alice and Barbara seem to agree about Claudia's proposed abortion, both saying it would be wrong or both denying that. It implies that Alice and Barbara must be understood as meaning different things, appearances notwithstanding.

An attempt might be made to reconcile such theories with our own views about what goes on in moral discourse by accounting for the perceived agreements and disagreements in terms of shared or conflicting attitudes that are expressed by such judgments. When Alice and Barbara disagree in their judgments, their difference is not propositional but rather attitudinal. They have, and their judgments express, different attitudes toward the act in question, one condemning the act (let us say) and the other refusing to condemn it. When they agree about the act, it is not that they make the same assertion but rather that they share an attitude toward the act, both condemning or both refusing to condemn it.

I do not wish to deny that attitudes are expressed by such judgments. The trouble with the suggestion is that Alice's and Barbara's beliefs may be ignored. But their beliefs are essentially connected with the relevant attitudes, in that the condemnatory attitude expressed by the judgment that Claudia's act would be wrong either is, or is grounded upon, the belief that Claudia's act would be wrong. So we cannot account for agreement or disagreement in such cases without deciding how the relevant beliefs are to be analyzed. Such theories are then committed to analyzing the beliefs relativistically along the lines adopted in construing the corresponding utterances. This simply returns us to the original decision of such theories, to reject clear logical phenomena in favor of preserving relativism.

It seems reasonable to say that such a relativist has incurred a sizable debt of explanation and justification. He must give very good reasons why we should regard apparently conflicting judgments as compatible and apparently identical judgments as different, and he must presumably show that they require analysis in one particular relativistic way rather than another. But what reasons are actually given? So far as I can see, they are not clearly reasons for analyzing moral judgments in a certain way.

The anthropologists who suggest such relativistic analyses seem tacitly to reason as follows: When individuals in a given society judge conduct, they typically invoke prevailing standards. Therefore, what it means to call an act "wrong" is that the act conflicts with the group's norms. This reasoning is painfully fallacious.

Harman suggests a different sort of argument for his relativistic analysis. His theory is limited to what he calls "inner" moral judgments-the ones we make when we judge it right or wrong of a particular person to do something or that some particular person ought or ought not to do something. Harman allows that we might judge a certain type of act nonrelativistically, even when we relativistically judge such conduct as performed by a given person.

The relevant part of Harman's reasoning may be summarized as follows: He gives examples to show that, when we judge a person's conduct, 
we take into account that person's own attitudes. We do not invoke considerations which we believe would not count as reasons for him, would not move him or influence his decision. These considerations are closely connected, in Harman's view, with that person's own moral standards. Thus, we refrain from saying that it is wrong of someone to do a certain thing (or that he ought not to do it) if we believe that he would not be moved by the considerations that concern us, or that his action conforms to his own moral code, even when we are ready to condemn the sort of conduct he practices. Therefore (Harman seems to reason), judgments to the effect that it is wrong of someone to do something (or that he ought not to do it) make essential reference to-by their very meaning invoke-that person's own attitudes and moral standards.

This amounts, in effect, to an agent theory, so Harman does not seem (does not perhaps intend) to endorse conflicting moral judgments. Because it is a rare attempt to justify a relativistic analysis, however, it merits our attention.

What concerns me is that the data assumed by Harman could equally well be accounted for in other ways-for example, by reference to our substantive convictions about the pointlessness of advising a person when we think we cannot influence him and, more generally, the unfairness of judging a person for doing something (as opposed to judging the sort of act he performs viewed more abstractly) by standards other than his own. We have no clear reason for rejecting this alternative account in favor of Harman's theory about the meaning of the relevant class of judgments. So we have no good reason to reject the nonrelativistic logical phenomena as illusory.

I mention Harman's case because I believe it typical. Relativistic analyses are not supported in the way they need to be. Now, it may be asked what all this shows. Have I succeeded in suggesting any more than that such theories are unfounded and perhaps implausible? That would be far from showing them untenable because of their incoherence.

But the only clear reason that we seem to have for resorting to relativistic analyses of moral judgments is that this will save the vulnerable forms of relativism from the scrap heaps of incoherence. As I suggested earlier, theory that avoids incoherence by arbitrary modifications, that lacks independent theoretical justification, cannot command our respect. My suggestion now is that similar considerations apply to theories that avoid incoherence through the same devices, not by deliberate design but, as it were, by luck or accident - for example, by fashionably formulating their claims as analyses of meaning, claims which, if formulated in other ways (which happen to be equally supported by the facts) would be untenable.

It looks as if relativism can be given a coherent gloss, even when it endorses conflicting moral judgments. But theories that avoid incoherence by such unjustified claims are, it seems, much worse than unfounded and implausible. 